
$\angle$ Research Square
Preprints are preliminary reports that have not undergone peer review.
They should not be considered conclusive, used to inform clinical practice,
or referenced by the media as validated information.

\title{
The Diversity Analysis and Functional Prediction of Endophytic Fungi Community of Gymnadenia Conopsea from Different Altitudes in Tibet
}

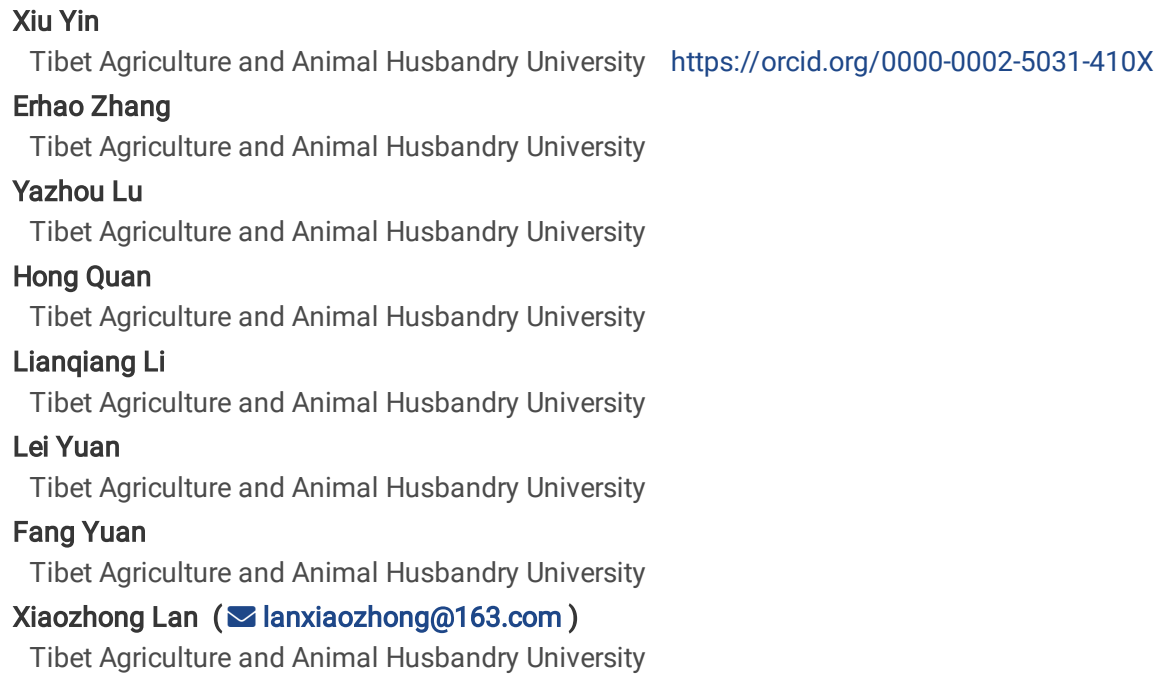




\section{Abstract}

Gymnadenia conopsea has high economic value, and can be used as a medicinal and ornamental plant. Due to its low natural reproduction rate and overexploitation, the extinction of this plant is gradually accelerating. Understanding the composition and diversity of endophytic fungi is of great significance in promoting its propagation and the utilization of beneficial fungal strains. In this study, the diversity of fungal communities from roots, stems, leaves, fruits, and soils at four different elevations was studied with Illumina MiSeq sequencing. A total of 3,707,871 sequences were detected from all samples, and the number of clustering OTUs was 14,800. The OTUs were assigned to 4 phyla, 17 classes, 41 orders, 73 families, and 99 genera. The predominant fungal groups included Ascomycota and Basidiomycota, accounting for $33.71 \%-86.38 \%$ and $6.98 \%-58.30 \%$ of the total species, respectively. According to the alpha diversity index analysis, the diversity and richness of endophytic fungal communities in plant tissues at low altitudes were higher than those at high altitudes, while the diversity and richness of soil fungi were the opposite. In addition, principal coordinate analysis (PCoA) not only showed that the fungal community structure was correlated with altitude but also indicated tissue specificity of the community structure. Our study explored the composition of the endophytic fungal community among different tissues from different altitudes and included functional analysis, which might provide new ideas for saving the endangered species G. conopsea.

\section{Introduction}

Gymnadenia conopsea, which is widely distributed in Ireland, England, Russia, Japan, Nepal, the Korean Peninsula, and China, is a perennial and terrestrial herb of the Gymnadenia genus in the Orchidaceae family (Lin et al. 2020). In Tibet, G. conopsea mainly grows in forests, grasslands, and waterlogged meadows at altitudes of 1,265-4,700 $\mathrm{m}$ (Shang et al. 2017). Previous studies have shown that the tubers of this species have important antifatigue (Zhao and Liu 2011), antioxidative (Morikawa et al. 2006), sedative and hypnotic (Lin 2009), immunoregulatory (Li et al. 2006), antiaging (Si and Liu 2013), and antihyperlipidemic activities (Zhang et al. 2013). In recent years, tubers have also been used as an ingredient and tonic added to food by the local people in Tibet to strengthen their bodies and prevent illness (Shang et al. 2017). Due to overexploitation, habitat destruction, and its low natural reproductive capacity, the numbers of G. conopsea are decreasing rapidly (Shang et al. 2017; Lin et al. 2020; Gao et al. 2020). This species has been listed in the grade II section of endangered species by the Convention on International Trade in Endangered Species of Wild Fauna and Flora (CITES) (Lin et al. 2020). Therefore, it is urgent to protect the resources of this species.

Endophytes are a group of microorganisms with various morphologies, mainly including endophytic fungi and bacteria, that can enter into plants through the root cortex, wounds, or stomata and reside in different tissues or organs without causing any harm to the host plants (Tan and Zou 2001; Schulz and Boyle 2005; Kusari et al. 2013). The tiny seeds of orchids with high ornamental and medicinal value lack endosperm and enough nutrition for seed germination, resulting in a low seed germination rate (Rasmussen and Rasmussen 2009; Rasmussen et al. 2015). A large number of studies have reported that symbiotic fungi play important roles in the propagation and growth of orchids, for example, endophytic fungi can facilitate seed germination, protocorm growth, and seedling establishment (Brundrett 2002; Huynh et al. 2009; Bonnardeaux et al. 2007; Sathiyadash et al. 2012). In addition, endophytes have evolved in coordination with host plants for a long time to form mutualistic ecological relationships (Kogelet al. 2006; Cui et al. 2018). Plant-associated microorganisms have metabolic activities that affect the host plants, improving plant resistance to biotic/abiotic stresses (Azcón-Aguilar and Barea 1997; Niones and Takemoto 2014). It has been reported in the literature that endophytic fungi have the ability to produce secondary metabolites, continuously promote the accumulation of bioactive components of medicinal plants and improve their quality and quantity (Faeth and Fagan 2002; Jia et al. 2016; Chagas et al. 2017; Cui et al. 2017; Yang et al. 2018). Moreover, exploring the relationship between plants and endophytic fungi is also important, and few studies have been performed to determine whether endophytes are related to the synthesis of bioactive compounds in $G$. conopsea.

The soil environment is different at different altitudes, and the abundance of the microbial community in soils is mainly affected by different nutrient levels (Ren et al. 2018). It has been reported that the fungal community structure varies significantly with altitude, mainly because of changes in soil nutrients (Siles and Margesin 2016). Yuan et al (2018) showed that endophytic fungal community diversity tended to decrease with increasing altitude. Previous literature reported different diversities of endophytes in the roots of G. conopsea from two geographically distant locations (Lin et al. 2020), but the interference of climate differences could not be well excluded. There are few reports on the effects of the same geographical location at different altitudes on the endophytic community structure in different tissues and rhizosphere soils of $G$. conopsea.

In this study, we aimed to investigate the diversity and composition of endophytic fungi of $G$. conopsea and rhizosphere soils at sites with different elevations and to further analysis their potential functions. Our results are expected to provide a basis for the conservation and artificial cultivation of endangered species and provide new insights for the development and utilization of fungi that produce bioactive substances.

\section{Materials And Methods Sample collection and treatment}

Tissue samples (roots, stems, leaves, and fruits) and rhizosphere soils of G. conopsea were collected from four sites in Nyingchi City, Tibet, China (Table 1). Three samples of each type were collected, for a total of 60 samples. The collected samples were randomly packed in sterile plastic bags and brought to the laboratory. All plant tissue samples were washed with running water and cut into 1-2 cm segments. Then, the samples were surface-sterilized with $75 \%$ ethanol for $30 \mathrm{~s}$ and $10 \%$ sodium hypochlorite for $5 \mathrm{~min}$. The treated samples were washed repeatedly three times with sterile distilled water and dried on petri dishes. To test the sterilization procedure, the sterile water was incubated after the treatment to observe whether colonies were formed, and the absence of microorganisms indicated effective surface sterilization. 
Table 1

Information on geographic locations and sample codes

\begin{tabular}{|lllll|}
\hline Location code & Sampling Site & Latitude & Longtiude & Altitude \\
\hline FM & Discarded Timber Mill (LuLang Township) & $29^{\circ} 46^{\prime} 04.16^{\prime \prime} \mathrm{N}$ & $94^{\circ} 43^{\prime} 53.13^{\prime \prime} \mathrm{E}$ & 3244 \\
\hline LZ & Linzhi Landscape Platform (Sejila Mountain) & $29^{\circ} 33^{\prime} 30.70^{\prime \prime} \mathrm{N}$ & $94^{\circ} 33^{\prime} 36.70^{\prime \prime} \mathrm{E}$ & 3525 \\
\hline LH & LinHai Landscape Platform (Sejila Mountain) & $29^{\circ} 37^{\prime} 00.85^{\prime \prime} \mathrm{N}$ & $94^{\circ} 41^{\prime} 51.90^{\prime \prime} \mathrm{E}$ & 4295 \\
\hline LD & Radar Station (Sejila Mountain) & $29^{\circ} 37^{\prime} 05.95^{\prime \prime} \mathrm{N}$ & $94^{\circ} 40^{\prime} 57.21^{\prime \prime} \mathrm{E}$ & 4513 \\
\hline
\end{tabular}

DNA extraction, PCR amplification and sequencing

Total DNA was extracted from all samples using fungal genomic DNA extraction kits (Solarbio, D2300). Afterwards, the quality of extracted DNA was assessed with $1 \%$ agarose gel electrophoresis, and the concentration and purity were determined with a NanoDrop 2000 UV-vis spectrophotometer (Thermo Scientific, Wilmington, USA). The primers ITSIF (5'-CTTGGTCATTTAGAGGAAGTAA-3') and ITS2R (5'-GCTGCGTTCTTCATCGATGC-3') were used to amplify the ITS1 region of all fungal samples, PCR amplification was performed using a $20 \mu \mathrm{L}$ reaction system $(5 \times$ TransStart FastPfu buffer $4 \mu \mathrm{L}, 2.5 \mathrm{mM}$ dNTPs $2 \mu \mathrm{L}, 5$ $\mu \mathrm{M}$ primer ITSIF $0.8 \mu \mathrm{L}, 5 \mu \mathrm{M}$ primer ITS2R $0.8 \mu \mathrm{L}$, TransStart FastPfu DNA Polymerase $0.4 \mu \mathrm{L}$, template DNA $10 \mathrm{ng}$, and ddH20 up to $20 \mu \mathrm{L})$ and the PCR procedure was as follows: initial denaturation at $95^{\circ} \mathrm{C}$ for $3 \mathrm{~min}$, followed by 27 cycles of denaturation at $95^{\circ} \mathrm{C}$ for $30 \mathrm{~s}$, annealing at $55^{\circ} \mathrm{C}$ for $30 \mathrm{~s}$ and extension at $72{ }^{\circ} \mathrm{C}$ for $45 \mathrm{~s}$, and single extension at $72{ }^{\circ} \mathrm{C}$ for $10 \mathrm{~min}$, following by a hold at $4{ }^{\circ} \mathrm{C}$. PCR products were detected with $2 \%$ agarose gel electrophoresis. An AxyPrep DNA gel extraction kit (Axygen Biosciences, Union City, CA, USA) was used for the purification of the products. The purified products were sent to Shanghai Majorbio Biopharm Technology Co., Ltd. for sequencing, and the sequences were deposited into the NCBI Sequence Read Archive (SRA) database (Accession Number: PRJNA699676).

\section{Analysis of soil physicochemical properties}

All the soil samples were air dried and then screened to remove debris. The electrical conductivity (EC), pH, and total nitrogen (TN) content were measured according to Chen et al (2019). The total phosphorus (TP) and available phosphate (AP) contents were measured with the Bray and Kurtz method (1945). The total potassium (TK) and available nitrogen (AN) contents were measured by the Lu method (Lu 1999). The soil organic matter (SOM) was measured using the Bell et al method (2020).

\section{Sequence processing and diversity analysis}

The raw gene sequencing reads were quality-filtered and merged by FLASH (Magoč and Salzberg 2011). Operational taxonomic units (OTUs) with 97\% similarity cutoff were clustered using UPARSE (version 7.0.1), and chimeric sequences were removed (Edgar 2013). The taxonomy of each OTU representative sequence was analyzed by RDP Classifier (version 2.2) (Zhao et al. 2018) against the UNITE database (version 8.0) (Kãuljalg et al. 2013) using a confidence threshold of $70 \%$. Alpha diversity, including the Sobs, Chao, Shannon, and coverage indices, was determined for all samples using Mothur (version 1.30 .2 ) to analyze the richness, diversity and coverage of the microbial community (Cui et al. 2018). A venn diagram was used to analyze the number of common and unique species in multiple groups, which could intuitively show the composition similarities and overlap of species (Wang et al. 2019). Analysis of fungal community composition among all samples was performed with the R package at different taxonomic levels. Principal coordinate analysis (PCoA) was implemented with QIIME (v1.9.1) (Yuan et al. 2018). After the physicochemical properties of soils were tested, correlation analysis of environmental factors was carried out, including redundancy analysis (RDA) (Chen et al. 2019) and a correlation heatmap was created. PICRUSt2 software was used for functional prediction of the fungal community from samples with the ITS gene sequence database (Douglas et al. 2020).

\section{Results}

\section{Richness and diversity analysis of the fungal community}

A total of 3,707,871 high-quality sequences from the stem, leaf, fruit, root, and soil samples collected from four sampling sites were obtained after read-quality filtering. The number of sequences in all samples of $G$. conopsea ranged from 47,235 to 68,027, with an average length of 237.5 bp (Table 2 ). The obtained sequences were clustered into 14,800 OTUs at a $97 \%$ similarity level with the removal of low-abundance OTUs, ranging from 247 to 1,453 .

All rarefaction curves showed that the number of OTUs reached saturation (99\%), indicating sufficient coverage of all fungal communities for further analysis (Fig. 1). The alpha diversity indices, including Sobs, Chao, and Shannon indices, showed the richness and diversity of endophytes from all samples (Table 2). The Sobs index revealed that the richness of the fungal community in soils was the highest, followed by that in stems, and the lowest richness was in roots. Comparison of fungal community richness in four types of tissue samples from different sampling sites showed that the community richness from the FM location was the highest. The fungal richness in the stems and fruits collected at the LD sampling site was the lowest, while that in the leaves and roots of the LH site was the lowest. These results indicated that the community richness of endophytic fungi was affected by altitude, and the richness increased with decreasing altitude. According to the Shannon value, the highest diversity of the fungal community was found in soils, followed by stems, and the lowest diversity was found in roots. Among the four types of tissues, the diversity of endophytic fungi was highest at the FM site but lowest at the LD site, indicating that fungal diversity increased with decreasing altitude. Interestingly, the community diversity of soil fungi was higher at high altitudes (LH and LD) than at low altitudes (FM and LZ). The results implied that changes in the community richness and diversity of endophytic fungi and soil fungi were mainly governed by altitude. The plant tissues at the lowest altitude harbored the highest richness and diversity of the fungal community. 
Table 2

Alpha diversity indices and the number of fungal sequences

\begin{tabular}{|c|c|c|c|c|c|c|}
\hline Sample & Number of sequences & Number of OTUs & Sobs & Shannon & Chao & $\begin{array}{l}\text { Coverage } \\
(\%)\end{array}$ \\
\hline FMF & 62588.7 & 756 & $396 \pm 39.36 b c$ & $2.80 \pm 0.13 b c$ & $479.75 \pm 32.80 \mathrm{~cd}$ & 99.84 \\
\hline FML & 63507.7 & 1056 & $649.67 \pm 73.33 b$ & $4.08 \pm 0.37 a$ & $740.91 \pm 81.73 b c$ & 99.82 \\
\hline FMR & 64893 & 732 & $351.33 \pm 157.88 \mathrm{bc}$ & $3.14 \pm 0.65 b$ & $379.93 \pm 172.66 \mathrm{de}$ & 99.94 \\
\hline FMS & 62441.7 & 1095 & $592.33 \pm 200.12 b$ & $3.95 \pm 0.92 a b$ & $635.00 \pm 216.76 b c$ & 99.91 \\
\hline FMT & 47235 & 961 & $602.00 \pm 121.13 b$ & $2.75 \pm 0.87 \mathrm{bc}$ & $780.57 \pm 97.09 b$ & 99.57 \\
\hline LDF & 54174.7 & 276 & $158.33 \pm 21.01 \mathrm{c}$ & $2.11 \pm 0.16 c$ & $224.31 \pm 32.48 \mathrm{e}$ & 99.9 \\
\hline LDL & 63685.3 & 917 & $469.67 \pm 109.74 b c$ & $3.62 \pm 0.29 a b$ & $532.07 \pm 122.98 \mathrm{~cd}$ & 99.9 \\
\hline LDR & 63803.7 & 431 & $204.33 \pm 80.00 c$ & $2.65 \pm 1.03 b c$ & $220.68 \pm 73.93 e$ & 99.97 \\
\hline LDS & 65685 & 676 & $346.67 \pm 13.65 b c$ & $3.13 \pm 0.52 b$ & $389.14 \pm 17.66 \mathrm{~d}$ & 99.92 \\
\hline LDT & 58396.7 & 916 & $625.00 \pm 38.97 b$ & $3.77 \pm 0.16 a b$ & $747.83 \pm 45.64 \mathrm{bc}$ & 99.74 \\
\hline LHF & 61073.7 & 515 & $275.00 \pm 26.00 c$ & $2.70 \pm 0.33 b c$ & $327.70 \pm 2.39 \mathrm{de}$ & 99.91 \\
\hline LHL & 66887.7 & 777 & $445.67 \pm 86.90 b c$ & $3.68 \pm 0.70 a b$ & $490.49 \pm 74.92 \mathrm{~cd}$ & 99.9 \\
\hline LHR & 52216.3 & 247 & $112.33 \pm 66.87 \mathrm{c}$ & $3.09 \pm 0.34 b$ & $119.33 \pm 66.38 \mathrm{e}$ & 99.99 \\
\hline LHS & 66149.3 & 811 & $454.67 \pm 149.86 b c$ & $4.15 \pm 0.58 a$ & $482.25 \pm 144.02 \mathrm{~cd}$ & 99.95 \\
\hline LHT & 68027 & 1453 & $958.33 \pm 126.26 a$ & $4.21 \pm 0.59 a$ & $1151.80 \pm 110.14 a$ & 99.65 \\
\hline LZF & 67925 & 461 & $248.33 \pm 77.36 c$ & $2.96 \pm 0.11 b$ & $299.48 \pm 118.92 \mathrm{de}$ & 99.92 \\
\hline LZL & 66937 & 947 & $559.00 \pm 76.37 \mathrm{bc}$ & $4.03 \pm 0.29 a c$ & $607.59 \pm 66.94 c$ & 99.89 \\
\hline LZR & 49307.3 & 284 & $124.67 \pm 17.24 \mathrm{c}$ & $2.99 \pm 0.23 b$ & $142.58 \pm 35.87 \mathrm{e}$ & 99.98 \\
\hline LZS & 63374.3 & 677 & $392.33 \pm 35.56 b c$ & $4.29 \pm 0.17 a$ & $406.08 \pm 38.27 d$ & 99.96 \\
\hline LZT & 67648.3 & 812 & $563.33 \pm 58.23 b c$ & $2.70 \pm 0.22 b c$ & $705.17 \pm 48.95 b c$ & 99.77 \\
\hline \multicolumn{7}{|c|}{$\begin{array}{l}\text { Note: Statistical significance assessed by ANOVA }(p<0.05) \text { is indicated with different lowercase letters. FMF, FMS, FMR, FML, and FMT, respectively, } \\
\text { represent fruits, stems, roots, leaves, and soils collected at the discarded timber mill; LDF, LDS, LDR, LDL, and LDT, respectively, represent fruits, stems, } \\
\text { roots, leaves, and soils collected from the radar station; LZF, LZS, LZR, LZL, and LZT, respectively, indicate fruits, stems, roots, leaves, and soils collected a } \\
\text { the Linzhi landscape platform; LHF, LHS, LHR, LHL, and LHT, respectively, indicate fruits, stems, roots, leaves, and soils collected at the LinHai landscape } \\
\text { platform. }\end{array}$} \\
\hline
\end{tabular}

According to the venn diagram (Fig. 2), significant differences in OTUs were found in tissue and soil samples of G. conopsea. Among all samples, the number of OTUs was the highest in the soils, followed by the leaves, and the lowest in the roots, at 2719, 2260, and 1189 (Fig. 2 A). The richness of OTUs in stems (2073 OTUs) was higher than that in fruits (1286 OTUs). There were 252 shared OTUs in stems, leaves, and fruits. The number of OTUs in both roots and soils was 172, while that specifically in roots and soils was 184 and 1325, respectively. The number of OTUs in tissue samples was the highest at the lowest altitude (FM site), but the results were different for soils, with the most OTUs at the high-altitude LH site. The lowest numbers of OTUs in fruits and stems were at the high-altitude LD site, and the lowest numbers in roots and leaves were at the LD site. The number of overlapping OTUs in fruits, roots, stems, leaves, and soils at the four sampling points was 101,46,140,172, and 120, respectively. Our data implied that the amount of OTUs in plant tissues varied with altitude.

\section{Analysis of endophytic fungi community composition}

The sequences obtained from all samples were annotated and analyzed from the phylum to genus levels. In our study, the community composition of endophytic fungi varied among the different tissues and rhizosphere soils at different sampling locations. All the OTUs were analyzed at the phylum level, and 4 main phyla were predominant (Fig. 3A). Ascomycota was the dominant phylum with the highest relative abundance in all samples, accounting for $33.71 \%-86.38 \%$, followed by Basidiomycota (6.98\%-58.30\%). The abundance of Ascomycota in fruits, leaves, and stems was significantly correlated with altitude, with high abundance at low altitude. In contrast, Basidiomycota in all samples were more abundant at higher elevations. Mortierellomycota existed only in roots and soils, with the highest relative abundance in the roots at the LZ collection site.

The sequences were classified into 73 families, which showed that the composition of the fungal community was different among different samples (Fig. 3B). The relative abundances of Cladosporiaceae, Leptosphaeriaceae, Bulleribasidiaceae, and Helotiaceae were the highest in fruits, stems, leaves and roots, respectively. The most dominant group in fruits was Cladosporiaceae, occupying $20.77-31.87 \%$, with the highest relative abundance at the lowest elevation, while this family was rare in stems and leaves and almost completely absent in soils. Leptosphaeriaceae was the predominant phylum of stems and showed a clear upward trend with elevation. Interestingly, the same phenomenon was observed in leaves but not in fruits. Bulleribasidiaceae predominated in the leaves, and the relative abundance ranged from 10.38-20.95\%. The higher abundances of Bulleribasidiaceae at high altitudes were more pronounced in fruits and leaves than in stems. Helotiales_fam_incertae_sedis was the most dominant fungus in roots except at the high-altitude LD site, accounting for $18.33 \%-25.0 \%$, while the abundance in stems and soils was less than $9 \%$. It is worth noting that the relative abundance of Herpotrichiellaceae in the roots 
collected from the LD site reached the highest at $36.11 \%$, while the relative abundance in other roots was lower than $8.43 \%$. Six families of fungi only existed in the soils and roots, including Mortierellaceae, Russulaceae, Inocybaceae, Atheliaceae, Clavariaceae, and Leotiaceae, whose relative abundances were also inconsistent. The dominant fungal species found only in rhizosphere soils included members of the Archaeorhizomycetaceae, Thelephoraceae,

Serendipitaceae, Hygrophoraceae, and Venturiaceae. The results illustrated that the abundance varied not only among the same types of tissues from different growth sites but also significantly varied among different tissue types. The abundances of communities between the rhizosphere soils and roots were different at the family level, but there were similarities in composition.

To further reveal the abundance and structure of the fungal community across the plant tissues and soils at the genus level, we performed heatmap analysis, to elucidate the distribution of the top 50 most abundant genera in the endophytic communities. As shown in Fig. 4, the distribution and structure of fungal communities were different among different sample types. For example, the fungal abundance in the roots and soils differed at the genus level. The distribution and abundance of several fungi, including Cladosporium, Rachicladosporium, Protomyces, Vishniacozyma, and Heterocephalacria, in the stems, leaves, and roots were higher than those in the fruits and soils. In addition, the abundance of Archaeorhizomyces varied among different types of samples, with the highest abundance in soils and increasing with elevation. Cadophora had the highest abundance in roots, followed by stems, and the abundance varied greatly at different altitudes. We observed from the heatmap that the fungal structure from different sample types, such as soils and fruits, was significantly different, while the same types had similar community structures. Compared with sample type, altitude had less effect on fungal community composition.

\section{Comparative analysis of endophytic fungal communities at different elevations}

To explore differences or similarities in the microbial community composition between samples, principal coordinate (PCoA) analysis based on Bray-Curtis distances was used to show that the between-sample distance reflected a similar composition between microbial communities at the OTU level (Fig. 5). The closer the samples were, the more similar the species composition was. In Fig. 5A, the roots and rhizosphere soils were grouped together and more concentrated, which implied that their community structures were similar. The plant tissues (leaves, fruits, and stems) formed separate clusters that were relatively dispersed. The results suggested that there were similar community structures among the roots and soils, which obviously differed from those of the other tissues. In addition to roots, the samples from plant tissues at the FM and LZ sites at low altitudes were more aggregated than those at the high altitude sits of LH and LD, which implied that community compositions were similar. The results indicated that the community structure was not only related to the sample type but also to altitude. This was also demonstrated in Fig. 5B. The points of the samples from the LH and LD sites were closer than those of the other sites, indicating that they were more similar in community structure. The distances of the fungal communities at the FM and LZ sites were closer, and the species compositions were more similar. The similarity of fungal groups might have relatively strong linkages to altitude.

\section{Influence of soil characteristics on the fungal community structure in different samples}

The soil samples collected from four sites were measured, and 8 indices of soil characteristics were determined, including total phosphorus (TP), total potassium (TK), total nitrogen (TN), available nitrogen (AN), pH, electrical conductivity (EC), available phosphorus (AP), and soil organic matter (SOM) (Table 3). Redundancy analysis (RDA) was used to explore the relationship between soil environmental factors and microbial community structure in all samples (Fig. 6A). Six of eight environmental factors significantly influenced the composition of the microbial community $(P<0.05)$, including TP $\left(r^{2}=0.186\right.$, $p=0.005)$, TK $\left(r^{2}=0.382, p=0.001\right), \mathrm{AN}\left(r^{2}=0.208, p=0.01\right), \mathrm{pH}\left(r^{2}=0.594, p=0.001\right), \mathrm{EC}\left(r^{2}=0.297, p=0.001\right)$, and SOM $\left(r^{2}=0.133, p=0.024\right)$, while TN $\left(r^{2}=\right.$ $0.0267, p=0.46)$ was largely irrelevant, followed by $\operatorname{AP}\left(r^{2}=0.097, p=0.058\right)$. Different types of samples from the same sampling site were grouped into a cluster, but the samples from the LH and LD sites were more concentrated than those from the low-altitude FM and LZ sites. Among the environmental factors, $\mathrm{pH}, \mathrm{SOM}, \mathrm{EC}$, and TK were negatively correlated with plant tissues and rhizosphere soils collected at FM site compared with TP and AN. However, SOM, EC, and TK were positively correlated with the samples at the LZ point. AN was negatively correlated with LH and LD samples. These results implied that the soil environment influenced the fungal community in all samples among different sites.

Table 3

The soil properties at the four sampling sites

\begin{tabular}{|c|c|c|c|c|c|c|c|c|}
\hline Sample & $\mathrm{TP} \mathrm{g} / \mathrm{kg}$ & $\mathrm{TK}^{+} \mathrm{g} / \mathrm{kg}$ & $\mathrm{TN} \mathrm{g} / \mathrm{kg}$ & $\mathrm{AN} \mathrm{g} / \mathrm{kg}$ & $\mathrm{pH}$ & $\mathrm{EC}$ us/cm & AP mg/kg & SOM g/kg \\
\hline LD & $0.62 \pm 0.04$ & $8.32 \pm 0.61$ & $2.69 \pm 0.94$ & $0.20 \pm 0.00$ & $6.2 \pm 0.03$ & $32.6 \pm 1.80$ & $12.60 \pm 3.14$ & $74.3 \pm 2.79$ \\
\hline $\mathrm{LH}$ & $0.68 \pm 0.09$ & $6.88 \pm 0.35$ & $2.63 \pm 1.27$ & $0.21 \pm 0.01$ & $6.2 \pm 0.18$ & $52.0 \pm 1.60$ & $9.88 \pm 2.17$ & $78.1 \pm 2.74$ \\
\hline LZ & $0.52 \pm 0.01$ & $9.03 \pm 0.21$ & $2.83 \pm 0.05$ & $0.21 \pm 0.01$ & $6.1 \pm 0.05$ & $48.6 \pm 2.26$ & $9.56 \pm 0.54$ & $90.0 \pm 1.83$ \\
\hline FM & $0.71 \pm 0.01$ & $4.68 \pm 0.15$ & $2.31 \pm 0.03$ & $0.20 \pm 0.01$ & $5.6 \pm 0.06$ & $24.0 \pm 1.18$ & $9.26 \pm 0.90$ & $58.4 \pm 1.79$ \\
\hline
\end{tabular}

To further evaluate the correlation between the fungal community composition and the environmental factors, we analyzed the correlation heatmap using the Spearman correlation coefficients at the genus level (Fig. 6B). The six environmental factors, including TP, EC, TK, pH, and SOM, exerted a more significant impact on the microbial community structure than AP and TN, which was consistent with the RDA results. For the top 50 most abundant genera of the fungal communities, unclassified_o_Chaetothyriales, Trichomerium, Russula, unclassified_c_Eurotiomycetes, Cladophialophora, unclassified_f_Venturiaceae, Mrakia, Knufia, Cladophialophora, Ceratobasidium, and unclassified_o_Chaetothyriales were positively related to the total P content, while unclassified_f_Didymellaceae, unclassified_f_Hyaloscyphaceae, unclassified_c_Leotiomycetes, and Protomyces were negatively correlated. Interestingly, unclassified_f_Chaetothyriaceae and Trichomerium were negatively correlated with TK and pH. In addition, unclassified_c_Eurotiomycetes was positively correlated with TP but negatively correlated with EC, AN, TN, SOM, and TK, with significant differences. There were 7 species positively related to pH with significant differences, among which the $\mathrm{P}$ value of Inocybe was less than 0.001 . Both $\mathrm{pH}$ and TP were positively correlated with unclassified_f_Venturiaceae. 
Leucosporidium and Tetracladium were positively correlated with $\mathrm{pH}$ and EC. The correlation analysis verified that the differences in microbial structure were significant among the different soil environmental factors.

\section{Predicted functional profiles of the metagenome}

The abundance of the MetaCyc pathway was predicted using PICRUSt2 (Table S1). A total of 73 pathways were identified. Functional gene families were mainly involved in the circulation of carbon and the metabolism of amino acids, fatty acids, and nucleotides. Among these genes, the relative abundances of those related to aerobic respiration, fatty acid oxidation, the glyoxylate cycle, GDP-mannose biosynthesis, the pentose phosphate pathway, myoinositol biosynthesis, pyruvate fermentation, methyl ketone biosynthesis, and guanosine nucleotide degradation were markedly high. In addition, genes with several functions associated with palmitate biosynthesis I, sulfate reduction, and the superpathway of ubiquinol-6 biosynthesis were more abundant in soils and roots than in other tissues.

\section{Discussion}

In this study, we investigated the fungal community structure in different plant tissues and rhizosphere soils of G. conopsea sampled from four sites in Tabet through high-throughput sequencing to explore the relationship between endophytic fungi and plants from a deeper perspective, with the aim of exploring the role of endophytic fungi and laying the foundation for the development and utilization of endophytic fungal resources.

A total of 14,800 OTUs belonging to 4 phyla, 73 families, and 99 genera obtained from tissues and rhizosphere soils were analyzed. It was previously reported that mycorrhizal fungi associated with orchids were mainly Basidiomycota and Ascomycota (Sisti et al. 2019). In our study, Ascomycota (33.71\%-86.38\%) was the dominant phylum, with the highest relative abundance in all samples, followed by Basidiomycota (6.98\%-58.30\%), while Mortierellomycota had the lowest relative abundance and existed only in roots and soil. These findings were similar to previous studies by Lin et al. (2020), who explored the differences in fungal communities from the roots and soils of $G$. conopsea. We also found that the community abundances of endophytes and soil fungi were different at the four sampling sites. The abundance of Ascomycota in fruits, leaves, and stems at low altitudes was higher than that at high altitudes, while the abundance in roots and soils was not consistent. Interestingly, the abundance of Basidiomycota was the opposite, with higher abundance at higher altitudes.

Several studies have shown that endophytes are closely related to the growth of Orchidaceae plants, playing important roles in the germination of Orchidaceae seeds (Bidartondo and Read 2008; Rasmussen 2002; Rasmussen et al. 2015), protocorm formation (Vujanovic et al. 2000), and seedling growth (Hou and Guo 2009; Huang et al. 2018), such as providing nutrients (Bonnardeaux et al. 2007; Sathiyadash et al. 2012; Kuga et al. 2014), secreting phytohormones to promote plant development (Zhang et al. 1999; Shah et al. 2019), and improving resistance against phytopathogens (Favre-Godal et al. 2020). Previous reports have shown that endophytes, including Tulasnellaceae, Ceratobasidiaceae, and Serendipitaceae, separated from orchids were cocultured with orchid seeds and could promote seed germination and protocorm development (Chen et al. 2012; Herrera et al. 2016; Meng et al. 2019). Gao et al (2020) isolated three kinds of endophytes from G. conopsea and observed that only the family Ceratobasidiaceae could promote protocorm formation and seedling growth. In this research, Ceratobasidiaceae was detected at a higher relative abundance in roots than in the other samples. The relative abundance of the species from the four collection sites was different, with the highest abundance at the FM site (14.19\%). Fungi belonging to Serendipitaceae were detected only in soils but not in plant tissues. Lin et al (2020) showed that there were differences in the community diversity of endophytes at different stages of plant development. We used plant tissues of G. conopsea at the fruit stage as the study material and failed to find Tulasnellaceae, which might explain its absence among the classified fungi.

Plant hormones, including GA, IAA, and abscisic acid, are produced by some of the endophytic fungi that have been separated from medicinal orchids (Zhang et al. 1999). The literature has shown that the secretion of phytohormones by endophytic fungi belonging to the genera Fusarium (Vujanovic et al. 2000; Tsavkelova et al. 2008; Bell et al. 2020), Gibberella (Silva et al. 2018), Leptosphaerulina (Favre-Godal et al. 2020), Trichoderma (Zhang et al. 2016), Cladosporium (Favre-Godal et al. 2020), Phialophora (Berthelot et al. 2016), Aspergillus (Yuan et al. 2018), and Cadophora (Berthelot et al. 2016) might explain why endophytes promote seed germination and plant growth. In the current study, Cladosporium and Cadophora were the dominant species, with different degrees of richness in different tissue samples. Among them, Cladosporium was the dominant genus in fruits, accounting for a relative abundance of $10.11 \%-21.96 \%$, and the abundance in stems was less than $5 \%$; this genus was barely detected in other samples. These results imply that this species plays an important role in fruit development of G. conopsea. The abundance of Cadophora was the highest in roots, and this genus was confirmed by Berthelot et al (2016) to enhance plant growth. Ceratobasidium also had the highest abundance in roots. Ercole et al (2015) observed mycorrhizal fungi such as Ceratobasidium with diverse communities in the roots and protocorms of photoautotrophic orchids. N uptake from inorganic sources and transport to the protocorm by the genus Ceratobasidium were revealed by Kuga et al. (2014). However, the abundances of Phialophora and Aspergillus were only $1.22 \%-5.25 \%$ in roots, but that of Gibberella was less than $5 \%$ and $1 \%$ in stems and leaves, respectively, which might also contribute to the extinction of $G$. conopsea. The symbiotic relationship between orchid plants and endophytes exerts a significant influence on the growth and natural propagation of orchids. In other words, the distribution of fungi could affect key stages of orchids, such as seed germination, plant growth and survival (McCormick et al. 2018). Similar reports demonstrated that the diversity and abundance of endophytes affected the distribution and characteristics of plants, such as the size of populations and density of plants (McCormick et al. 2018; Favre-Godal et al. 2020). According to the results, one of the reasons why G. conopsea has become endangered in Tibet may be related to the low diversity and abundance of specific endophytic fungal communities that could promote plant growth and reproduction. Our results could provide a reference for the introduction of fungi into habitat soil to colonize roots to expand the population and protect the species.

According to the venn diagram analysis, the number of overlapping OTUs in roots and soils was 172. PCoA results showed that OTUs from roots and rhizosphere soils were clustered together. Compared with other plant tissues (stems, leaves, and fruits), the fungal community structures in roots and rhizosphere soils were more similar. The results implied that endophytes in roots might originate from rhizosphere soils. McCormick et al (2012) suggested that fungal community diversity was influenced by the soil environment. Supporting this view, Bell et al (2020) also showed that the diversity of endophytes in the roots of orchids was related to the soil environment. RDA indicated that the soil environment exerted a significant influence on the fungal community. In 
this study, the low abundance of fungal communities associated with plant growth promotion might be affected by the soil environment, which may be one of the reasons for the endangerment of G. conopsea in Tibet.

Endophytes can not only promote plant growth but also produce bioactive components (Sisti et al. 2019). Endophytic fungi from medicinal plants can synthesize many of the same or similar bioactive substances as their host plants (Yang et al. 2018). Relevant reports have shown that endophytes in medicinal plants have pharmacologically active compounds, such as antioxidants, antibacterial compounds, and tumor growth inhibitors (Sarsaiya et al. 2019), which Ma et al (2015) indicated was related to the diversity of endophytic fungal metabolites. All the sequences were classified into 73 families, among which Cladosporiaceae and Leptosphaeriaceae were the dominant flora. Fu et al (2020) showed that Leptosphaeriaceae reduced asthma severity. The highest abundance of Leptosphaeriaceae was found in fruits at low altitudes, with a relative abundance of $19.734 \%-19.89 \%$, and this should be beneficial to the study and utilization of this dominant family. $\mathrm{Ng}$ et al (2013) declared that the genome of UM238, a dematiaceous fungus belonging to Herpotrichiellaceae, contained a variety of protective genes that helped the fungus survive in adverse environments. We also found that the abundance of Herpotrichiellaceae in roots was high, with the highest at the LD collection site; this family may aid G. conopsea adaptation to the environment of the Qinghai-Tibet Plateau, which is characterized by low temperature, strong UV ultraviolet light and low oxygen. Several species of Nectriaceae have previously been reported to have potential as biocontrol agents and biodegraders in industrial applications (Lombard et al. 2015; Ye et al. 2020). Similarly, the high abundance of these species in roots and rhizosphere soils in our results might make the plant more adaptable to the soil environment. In addition, secondary metabolites such as mycotoxins or antibiotics were secreted by several species belonging to the family Trichomeriaceae, which was described by Ye et al (2020). Trichomeriaceae were distributed in stems and leaves in our study. The analysis of the MetaCyc pathway with PICRUSt2 revealed several lipid metabolism pathways, such as fatty acid oxidation, CDP-diacylglycerol biosynthesis, stearate biosynthesis, phosphatidylglycerol biosynthesis, and monoacylglycerol metabolism. Interestingly, Mortierellaceae was distributed in roots and soils, with the highest abundance in roots. A large number of studies have shown that many species of Mortierellaceae are oleaginous fungi with great potential for yield of lipids and valuable fatty acids (Li et al. 2015; Gao et al. 2016). The MetaCyc pathway results also showed a high abundance of amino acids and carbohydrate metabolism. Amino acid metabolism mainly involved leucine, tyrosine, tryptophan, serine, valine, glycine, methionine, threonine, and arginine. Jiang et al (2018) isolated 9 kinds of amino acids from G. conopsea, which have high nutritional and medicinal value because they could maintain nitrogen balance in the body. Yu (2017) found that polysaccharides had the effect of delaying aging and alleviating fatigue through study of the pharmacological activity of polysaccharides in G. conopsea. Therefore, the metabolism of amino acids and carbohydrates in endophytes might be beneficial for improving the nutritional and medicinal value of $G$. conopsea. The natural propagation rate of $G$. conopsea is low, artificial cultivation of this species is difficult, and human destruction of habitat is increasing, which will cause the population to decrease. To avoid the decline of $G$. conopsea caused by the exploitation and utilization of the species for medicinal resources, effective medicinal ingredients can be obtained from microorganisms by mass culture in the future. Our study aimed to analyze the fungal community diversity and composition of $G$. conopsea, which may be valuable for screening fungi with biological activity.

\section{Declarations}

AcknowledgementsThis research was supported financially by the Forth National Survey of Traditional Chinese Medicinal Resources Investigation in Tibet Aut 542329), Tibet Autonomous Region Major Special Science and Technology (grant no. XZ201901-GA-04), and Budget Project of Tibet Autonomous Region level (grant no. 2019-44).

Author contributions $X Y, E H Z$, and $Y Z L$ designed experiments, collected samples, and performed the experiments; $Y Z L, E H Z, F Y, L Y, H Q$, and HC performed the statistical analysis; $X Y$ completed the first draft of the manuscript; XZL and LQL modified the manuscript; all authors approved the submitted version of the manuscript.

\section{Disclosure statement}

No potential conflict of interest was reported by the authors.

\section{References}

1. Azcón-Aguilar C, Barea JM (1997) Arbuscular mycorrhizas and biological control of soil-borne plant pathogens-an overview of the mechanisms involved. Mycorrhiza 6(6):457-64. https://doi.org/10.1007/s005720050147

2. Bell J, Yokoya K, Kendon JP, Sarasan V (2020) Diversity of root-associated culturable fungi of Cephalanthera rubra (Orchidaceae) in relation to soil characteristics. Peer J 8:e8695. https://doi.org/10.7717/peerj.8695

3. Berthelot C, Leyval C, Foulon J, Chalot M, Blaudez D (2016) Plant growth promotion, metabolite production and metal tolerance of dark septate endophytes isolated from metal-polluted poplar phytomanagement sites. FEMS Microbiol Ecol 92(10):1-10. https://doi.org/10.1093/femsec/fiw144

4. Bidartondo MI, Read DJ (2008). Fungal specificity bottlenecks during orchid germination and development. Mol Ecol 17(16):3707-3716. https://doi.org/10.1111/j.1365-294X.2008.03848.x

5. Bonnardeaux Y, Brundrett M, Batty A, Dixon K, Koch J, Sivasithamparam K (2007) Diversity of mycorrhizal fungi of terrestrial orchids: compatibility webs, brief encounters, lasting relationships and alien invasions. Mycol Res 111:51-61. https://doi.org/10.1016/j.mycres.2006.11.006

6. Bray RH, Kurtz LT (1945) Determination of total, organic, and available forms of phosphorus in soils. Soil Science 59(1):39-45.

https://doi.org/10.1097/00010694-194501000-00006

7. Brundrett MC. (2002). Coevolution of roots and mycorrhizas of land plants. New Phytol 154(2):275-304. https://doi.org/10.1046/j.1469-

8137.2002.00397.x

Page $7 / 14$ 
8. Cui JL, Vijayakumar V, Zhang G (2018) Partitioning of fungal endophyte assemblages in root-parasitic plant Cynomorium songaricum and its host Nitraria tangutorum. Front Microbiol 9:666. https://doi.org/10.3389/fmicb.2018.00666

9. Cui JL, Wang YN, Jiao J, Gong Y, Wang JH, Wang ML (2017) Fungal endophyte-induced salidroside and tyrosol biosynthesis combined with signal crosstalk and the mechanism of enzyme gene expression in Rhodiola crenulata. Sci Rep 7(1):12540. https://doi.org/10.1038/s41598-017-12895-2

10. Chagas MBO, Prazeres Dos Santos I, Nascimento da Silva LC, Correia MTDS, Magali de Araújo J, Cavalcanti MDS, Lima VLM (2017) Antimicrobial activity of cultivable endophytic fungi associated with Hancornia Speciosa gomes bark. Open Microbiol J 11:179-188.

https://doi.org/10.2174/1874285801711010179

11. Chen J, Wang H, Guo SX (2012) Isolation and identification of endophytic and mycorrhizal fungi from seeds and roots of Dendrobium (Orchidaceae). Mycorrhiza, 22(4):297-307. https://doi.org/10.1007/s00572-011-0404-0

12. Chen PL, Zhao ML, Tang F, Hu YM, Peng XJ, Shen SH (2019) The effect of environment on the microbiome associated with the roots of a native woody plant under different climate types in China. Appl Microbiol Biotechnol 103(9):3899-3913. https://doi.org/10.1007/s00253-019-09747-6

13. Douglas GM, Maffei VJ, Zaneveld JR, Yurgel SN, Brown JR, Taylor CM, Huttenhower C, Langille MGI (2020) PICRUSt2 for prediction of metagenome functions. Nat Biotechnol 38:685-688. https://doi.org/10.1038/s41587-020-0548-6

14. Edgar RC (2013) UPARSE: highly accurate OTU sequences from microbial amplicon reads. Nat Methods 10(10):996-998. https://doi.org/10.1038/nmeth.2604

15. Ercole E, Adamo M, Rodda M, Gebauer G, Girlanda M, Perotto S (2015) Temporal variation in mycorrhizal diversity and carbon and nitrogen stable isotope abundance in the wintergreen meadow orchid Anacamptis morio. New Phytol 205(3):1308-1319. https://doi.org/10.1111/nph.13109

16. Faeth SH, Fagan WF (2002) Fungal endophytes: common host plant symbionts but uncommon mutualists. Integr Comp Biol 42(2):360-368. https://doi.org/10.1093/icb/42.2.360

17. Favre-Godal Q, Gourguillon L, Lordel-Madeleine S, Gindro K, Choisy P (2020) Orchids and their mycorrhizal fungi: an insufficiently explored relationship. Mycorrhiza 30(1):5-22. https://doi.org/10.1007/s00572-020-00934-2

18. Fu X, Norbäck D, Yuan QQ, Li YL, Zhu XH, Hashim JH, Hashim Z, Ali F, Zheng YW, Lai XX, Spangfort MD, Deng YQ, Sun Y (2020) Indoor microbiome, environmental characteristics and asthma among junior high school students in Johor Bahru, Malaysia. Environ Int 138:105664. https://doi.org/10.1016/j.envint.2020.105664

19. Gao MJ, Wang C, Zheng ZY, Zhu L, Zhan XB, Lin CC 2016 Improving arachidonic acid fermentation by Mortierella alpina through multistage temperature and aeration rate control in bioreactor. Prep Biochem Biotechnol 46(4):360-367. https://doi.org/10.1080/10826068.2015.1031397

20. Gao Y, Zhao ZY, Li JY, Liu N, Jacquemyn H, Guo SX, Xing XK (2020) Do fungal associates of co-occurring orchids promote seed germination of the widespread orchid species Gymnadenia conopsea? Mycorrhiza 30:221-228. https://doi.org/10.1007/s00572-020-00943-1

21. Herrera H, Valadares R, Contreras D, Bashan Y, Arriagada C (2017) Mycorrhizal compatibility and symbiotic seed germination of orchids from the Coastal Range and Andes in south central Chile. Mycorrhiza 27(3):175-188. https://doi.org/10.1007/s00572-016-0733-0

22. Hou XQ, Guo SX (2009) Interaction between a dark septate endophytic isolate from Dendrobium sp. and roots of $D$. nobile seedlings. J Integr Plant Biol 51(4):374-381. https://doi.org/10.1111/j.1744-7909.2008.00777.x

23. Huang H, Zi XM, Lin H, Gao JY (2018) Host-specificity of symbiotic mycorrhizal fungi for enhancing seed germination, protocorm formation and seedling development of over-collected medicinal orchid, Dendrobium devonianum. J Microbiol 56(1):42-48. https://doi.org/10.1007/s12275-018-7225-1

24. Huynh TT, Thomson R, McLean CB, Lawrie AC (2009) Functional and genetic diversity of mycorrhizal fungi from single plants of Caladenia formosa (Orchidaceae). Ann Bot 104(4):757-765. https://doi.org/10.1093/aob/mcp153

25. Jia M, Chen L, Xin HL, Zheng CJ, Rahman K, Han T, Qin LP (2016) A friendly relationship between endophytic fungi and medicinal plants: a systematic review. Front Microbiol 7:906. https://doi.org/10.3389/fmicb.2016.00906

26. Jiang HT, Ma B, Bi N, Ma CZ (2018) Composition analysis and quality evaluation of nutritional components of Gymnadenia conopsea邓L.『R. Br. from Linzhi. Food Research and Development 39(22):135-140.

27. Kogel KH, Franken P, Hückelhoven R (2006) Endophyte or parasite-what decides? Curr Opin Plant Biol 9 (4):358-363. https://doi.org/10.1016/j.pbi.2006.05.001

28. Kõljalg U, Nilsson RH, Abarenkov K, Tedersoo L, Taylor AFS, Bahram M et al (2013) Towards a unified paradigm for sequence-based identification of fungi. Mol Ecol 22:5271-5277. https://doi.org/10.1111/mec.12481

29. Kuga Y, Sakamoto N, Yurimoto H (2014) Stable isotope cellular imaging reveals that both live and degenerating fungal pelotons transfer carbon and nitrogen to orchid protocorms. New Phytologist 202(2):594-605. https://doi.org/10.1111/nph.12700

30. Kusari S, Pandey SP, Spiteller M (2013) Untapped mutualistic paradigms linking host plant and endophytic fungal production of similar bioactive secondary metabolites. Phytochemistry 91:81-87. https://doi.org/10.1016/j.phytochem.2012.07.021

31. Li XY, Lin Y, Chang M, Jin QZ, Wang XG (2015) Efficient production of arachidonic acid by Mortierella alpina through integrating fed-batch culture with a two-stage pH control strategy. Bioresour Technol 181:275-282. https://doi.org/10.1016/j.biortech.2015.01.009

32. Li M, Wang CL, Guo SX, Yang JS, Xiao PG (2006) Advances in studies on chemical constituents and pharmacological activities for plants of Gymnadenia R. Br. Chin Trad Herb Drug 37:1264.

33. Lin M, Xiong H, Xiang XC, Zhou ZL, Liang LF, Mei ZN (2020) The effect of plant geographical location and developmental stage on root-associated microbiomes of Gymnadenia conopsea. Front Microbiol 11:1257. https://doi.org/10.3389/fmicb.2020.01257

34. Lin ZC (2009) The pharmacology of Gymnadenia conopsea. Dissertation, Guangzhou University of Chinese Medicine 
35. Lombard L, van der Merwe NA, Groenewald JZ, Crous PW (2015) Generic concepts in Nectriaceae. Stud Mycol 80:189-245.

https://doi.org/10.1016/j.simyco.2014.12.002

36. Lu RK (1999) Methods of Soil Agricultural Chemical Analysis. China Agricultural Science and Technology Press, Beijing

37. Magoč T, Salzberg SL (2011) FLASH: fast length adjustment of short reads to improve genome assemblies. Bioinformatics 27(21):2957-2963. https://doi.org/10.1093/bioinformatics/btr507

38. Ma X, Kang J, Nontachaiyapoom S, Wen T, Hyde KD (2015) Non-mycorrhizal endophytic fungi from orchids. Current Science 109(1):72-87. https://www.jstor.org/stable/24905693

39. Meng YY, Zhang WL, Selosse M, Gao JY (2019) Are fungi from adult orchid roots the best symbionts at germination? A case study. Mycorrhiza 29:541547. https://doi.org/10.1007/s00572-019-00907-0

40. McCormick MK, Lee Taylor D, Juhaszova K, Burnett RK, Whigham DF, O'Neill JP (2012) Limitations on orchid recruitment: not a simple picture. Mol Ecol 21(6):1511-1523. https://doi.org/10.1111/j.1365-294X.2012.05468.x

41. McCormick MK, Whigham DF, Canchani-Viruet A (2018) Mycorrhizal fungi affect orchid distribution and population dynamics. New Phytol 219(4):12071215. https://doi.org/10.1111/nph. 15223

42. Morikawa T, Xie HH, Matsuda H, Wang T, Yoshikawa M (2006) Bioactive constituents from Chinese natural medicines. XVII. Constituents with radical scavenging effffect and new glucosyloxybenzyl 2- isobutylmalates from Gymnadenia conopsea. Chem Pharm Bull 54(4):506513. https://doi.org/10.1248/cpb.54.506

43. Ng KP, Yew SM, Chan CL, Tan RX, Soo-Hoo TS, Na SL, Hassan H, Ngeow YF, Hoh CC, Lee KW, Yee WY (2013) Draft genome sequence of Herpotrichiellaceae sp. UM 238 isolated from human skin scraping. Genome Announc 1(1):e00148-12. https://doi.org/10.1128/genomeA.00148-12

44. Niones JT, Takemoto D (2014) An isolate of Epichloë festucae, an endophytic fungus of temperate grasses, has growth inhibitory activity against selected grass pathogens. J Gen Plant Pathol 80(4):337-347. https://doi.org/10.1007/s10327-014-0521-7

45. Rasmussen HN (2002) Recent developments in the study of orchid mycorrhiza. Plant Soil 244:149-163. https://doi.org/10.1023/A:1020246715436

46. Rasmussen HN, Dixon KW, Jersáková J, Těitelová T (2015) Germination and seedling establishment in orchids: a complex of requirements. Ann Bot 116(3):391-402. https://doi.org/ 10.1093/aob/mcv087

47. Rasmussen HN, Rasmussen FN (2009) Orchid mycorrhiza: implications of a mycophagous life style. Oikos 118:334-345. https://doi.org/10.1111/j.16000706.2008.17116.x

48. Ren CJ, Zhang W, Zhong ZK, Han XH, Yang GH, Feng YZ, Ren GX (2018) Differential responses of soil microbial biomass, diversity, and compositions to altitudinal gradients depend on plant and soil characteristics. Sci Total Environ 750-758. https://doi.org/10.1016/j.scitotenv.2017.08.110

49. Sarsaiya S, Shi JS, Chen JS (2019) A comprehensive review on fungal endophytes and its dynamics on Orchidaceae plants: current research, challenges, and future possibilities. Bioengineered 10(1):316-334. https://doi.org/10.1080/21655979.2019.1644854

50. Sathiyadash K, Muthukumar T, Uma E, Pandey RR (2012) Mycorrhizal association and morphology in orchids. J Plant Interact 7(3):238-247. https://doi.org/10.1080/17429145.2012.699105

51. Schulz B, Boyle C (2005) The endophytic continuum. Mycol Res 109,661-687. https://doi.org/10.1017/s095375620500273x

52. Shah S, Shrestha R, Maharjan S, Selosse MA, Pan B (2019) Isolation and characterization of plant growth-promoting endophytic fungi from the roots of Dendrobium moniliforme. Plants 8(1):5. https://doi.org/10.3390/plants8010005

53. Shang XF, Guo X, Liu Y, Pan H, Miao XL, Zhang JY (2017) Gymnadenia conopsea (L.) R. Br.: A systemic review of the ethnobotany, phytochemistry, and pharmacology of an important Asian Folk Medicine. Front Pharmacol 8:24. https://doi.org/10.3389/fphar.2017.00024

54. Si Q, Liu TH (2013) Anti-aging effffect and mechanism of Shouzhangshen-37 Pill from Mongolian medicine on subacute aging mice. Chin J Exper Trad Med Formul 19:194.

55. Siles JA, Margesin R (2016) Abundance and diversity of bacterial, archaeal, and fungal communities along an altitudinal gradient in alpine forest soils: What are the driving factors? Microb Ecol 72(1):207-220. https://doi.org/10.1007/s00248-016-0748-2

56. Silva FA, Liotti RG, Boleti APA, Reis ÉM, Passos MBS, Dos SEL, Sampaio OM, Januário AH, Branco CLB, Silva GF, Mendonça EAF, Soares MA (2018) Diversity of cultivable fungal endophytes in Paullinia cupana (Mart.) Ducke and bioactivity of their secondary metabolites. PLoS One 13(4):e0195874. https://doi.org/10.1371/journal.pone.0195874

57. Sisti LS, Flores-Borges DNA, de Andrade SAL, Koehler S, Bonatelli ML, Mayer JLS (2019) The role of non-mycorrhizal fungi in germination of the mycoheterotrophic orchid Pogoniopsis schenckii Cogn. Front Plant Sci 10:1589. https://doi.org/10.3389/fpls.2019.01589

58. Tan RX, Zou WX (2001) Endophytes: a rich source of functional metabolites. Nat Prod Rep 18(4):448-459. https://doi.org/10.1039/b100918o

59. Tsavkelova EA, Bömke C, Netrusov Al, Weiner J, Tudzynski B (2008) Production of gibberellic acids by an orchid-associated Fusarium proliferatum strain. Fungal Genet Biol 45(10):1393-1403. https://doi.org/10.1016/j.fgb.2008.07.011

60. Vujanovic V, St-Arnaud M, Barabé D, Thibeault G (2000) Viability testing of orchid seed and the promotion of colouration and germination. Ann Bot 86(1):79-86. https://doi.org/10.1006/anbo.2000.1162

61. Wang LX, Ren LL, Li CC, Gao CL, Liu XB, Wang M, Luo YQ (2019) Effects of endophytic fungi diversity in different coniferous species on the colonization of Sirex noctilio (Hymenoptera: Siricidae). Sci Rep 9(1):5077. https://doi.org/10.1038/s41598-019-41419-3

62. Yang GD, Li P, Meng LF, Xv K, Dong FM, Qiu Y, He L, Lin L (2018) Diversity and communities of culturable endophytic fungi from different tree peonies (geoherbs and non-geoherbs), and their biosynthetic potential analysis. Braz J Microbiol 47-58. https://doi.org/10.1016/j.bjm.2018.06.006 
63. Ye FC, Gong DF, Pang CP, Luo JL, Zeng XM, Shang CG (2020) Analysis of fungal composition in mine-contaminated soils in Hechi City. Curr Microbiol 77(10):2685-2693. https://doi.org/10.1007/s00284-020-02044-w

64. Yu PZ (2017) Study on extract techniques and pharmacological activities of polysaccharide from Gymnadenia conopsea. Dissertation, Qinghai Normal University

65. Yuan XL, Cao M, Liu XM, Du YM, Shen GM, Zhang ZF, Li JH, Zhang P (2018) Composition and genetic diversity of the Nicotiana tabacum microbiome in different topographic areas and growth periods. Int J Mol Sci 19(11):3421. https://doi.org/10.3390/ijms19113421

66. Zhao L, Liu GQ (2011) Experimental study of Shouzhang Shen liquids on anti-fatigue effffects in mice. Clin J Chin Med 22:17.

67. Zhao Y, Xiong Z, Wu GL, Bai WX, Zhu ZQ, Gao YH, Parmar S, Sharma VK, Li HY (2018) Fungal endophytic communities of two wild Rosa varieties with different powdery mildew susceptibilities. Front Microbiol 9: 2462. https://doi.org/10.3389/fmicb.2018.02462

68. Zhang J, Wang C, Guo S, Chen J, Xiao P (1999) Studies on the plant hormones produced by 5 species of endophytic fungi isolated from medicinal plants (Orchidacea). Zhongguo Yi Xue Ke Xue Yuan Xue Bao, 21(6), 460-5.

69. Zhang TE, Chen CY, Li SH, Chen C, Liu WW, Yan ZY (2013) Effffect of the extract of Gymnadenia conopsea on the blood lipid and liver function in experimental hyperlipidemia rats. Lishizhen Med Mater Med Res 24:865.

70. Zhang SW, Gan YT, Xu BL (2016) Application of plant-growth-promoting fungi Trichoderma longibrachiatum T6 enhances tolerance of wheat to salt stress through improvement of antioxidative defense system and gene expression. Front Plant Sci 7:1405. https://doi.org/10.3389/fpls.2016.01405

\section{Figures}

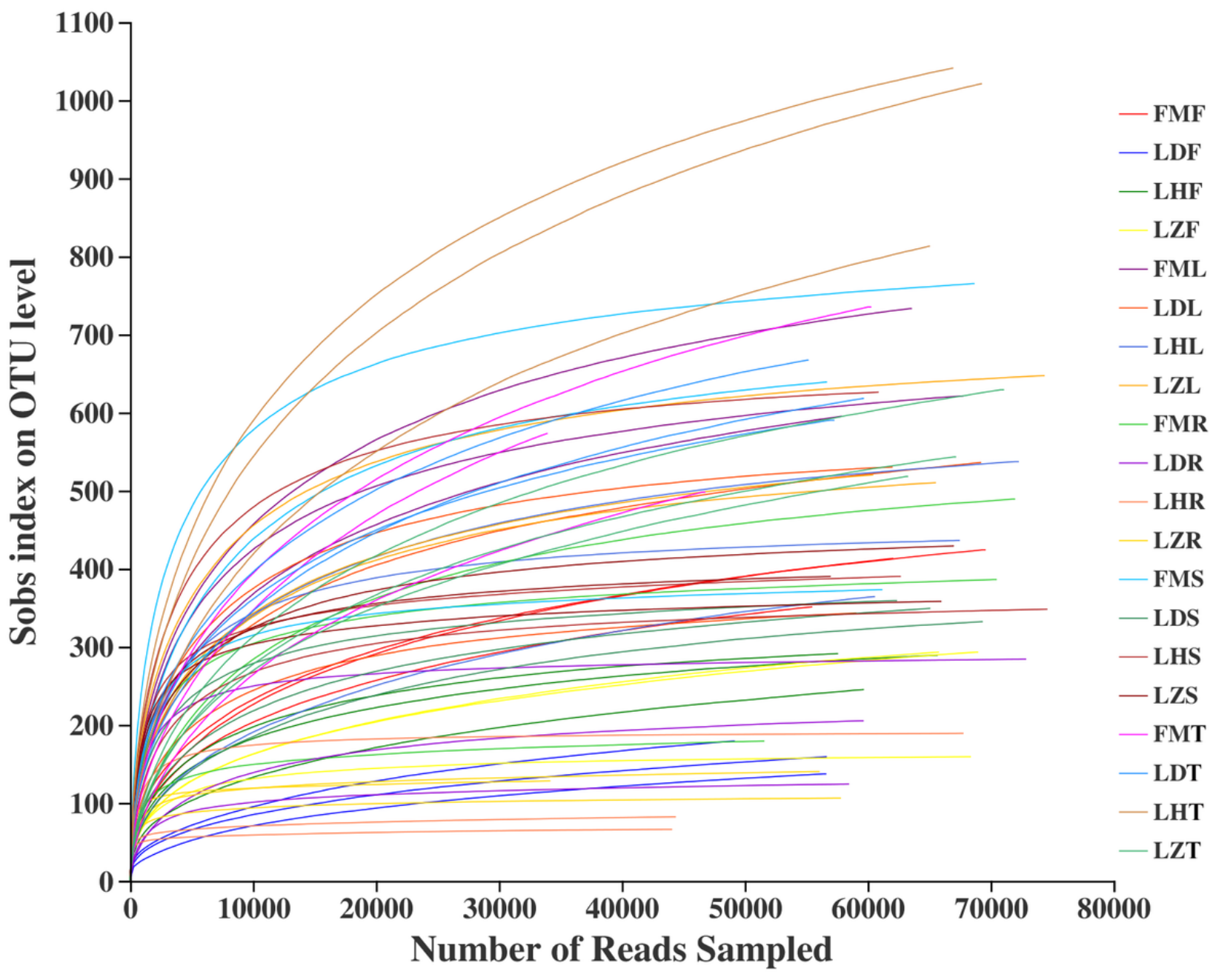

Figure 1

Rarefaction curve of fungal OTUs in different tissues and rhizosphere soil of G. conopsea. 
A
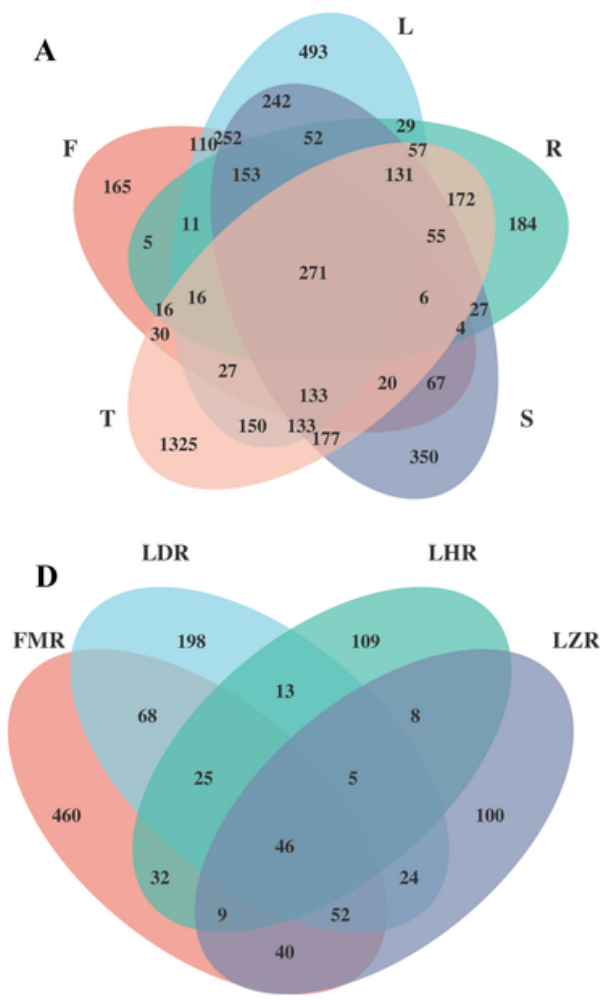

B

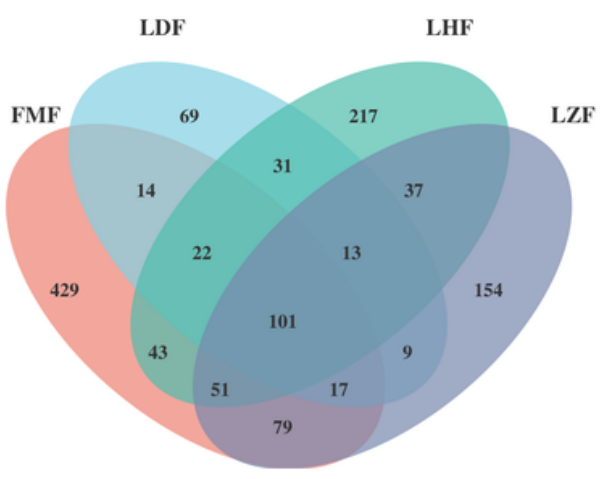

E

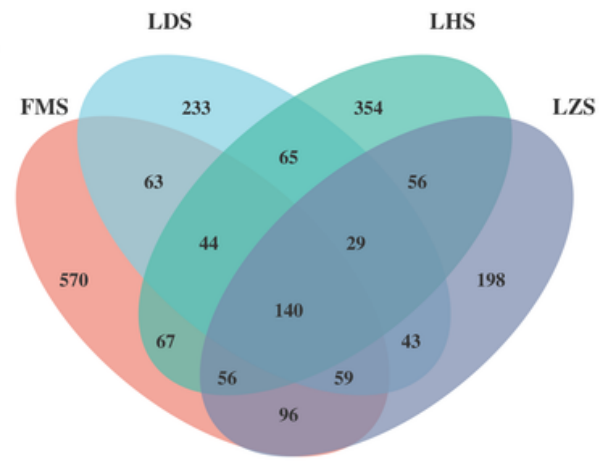

C
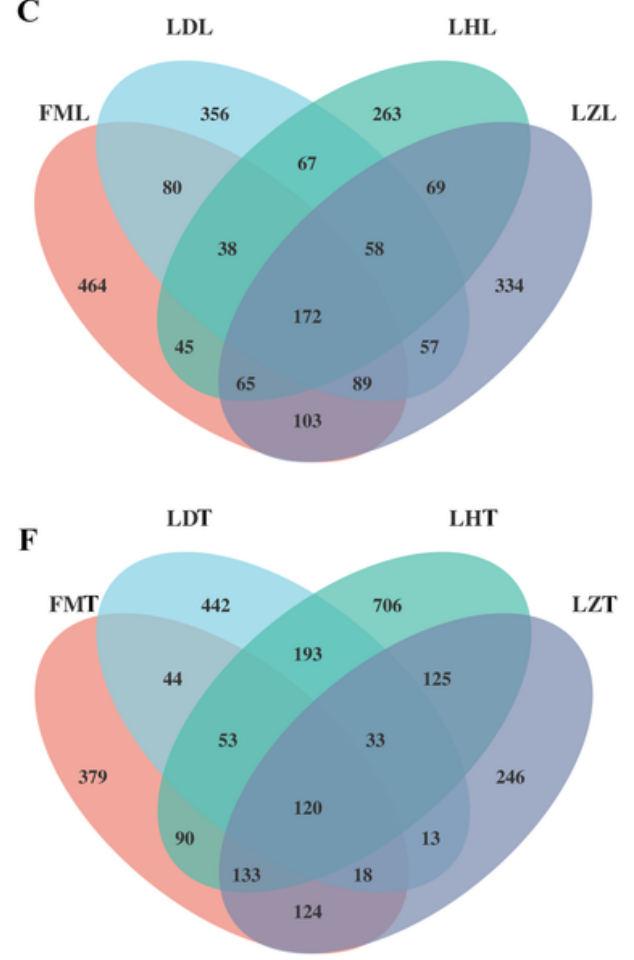

Figure 2

Venn diagram indicating the common and unique OTUs of fungal community members in all samples. A represents the number of fungal OTUs from all samples. B, C, D, E, and F show the number of OTUs in fruits, leaves, roots, stems, and soils at the four sampling sites, respectively. F: fruit, L: leaf, R: root, S: stem, and T: soil. 

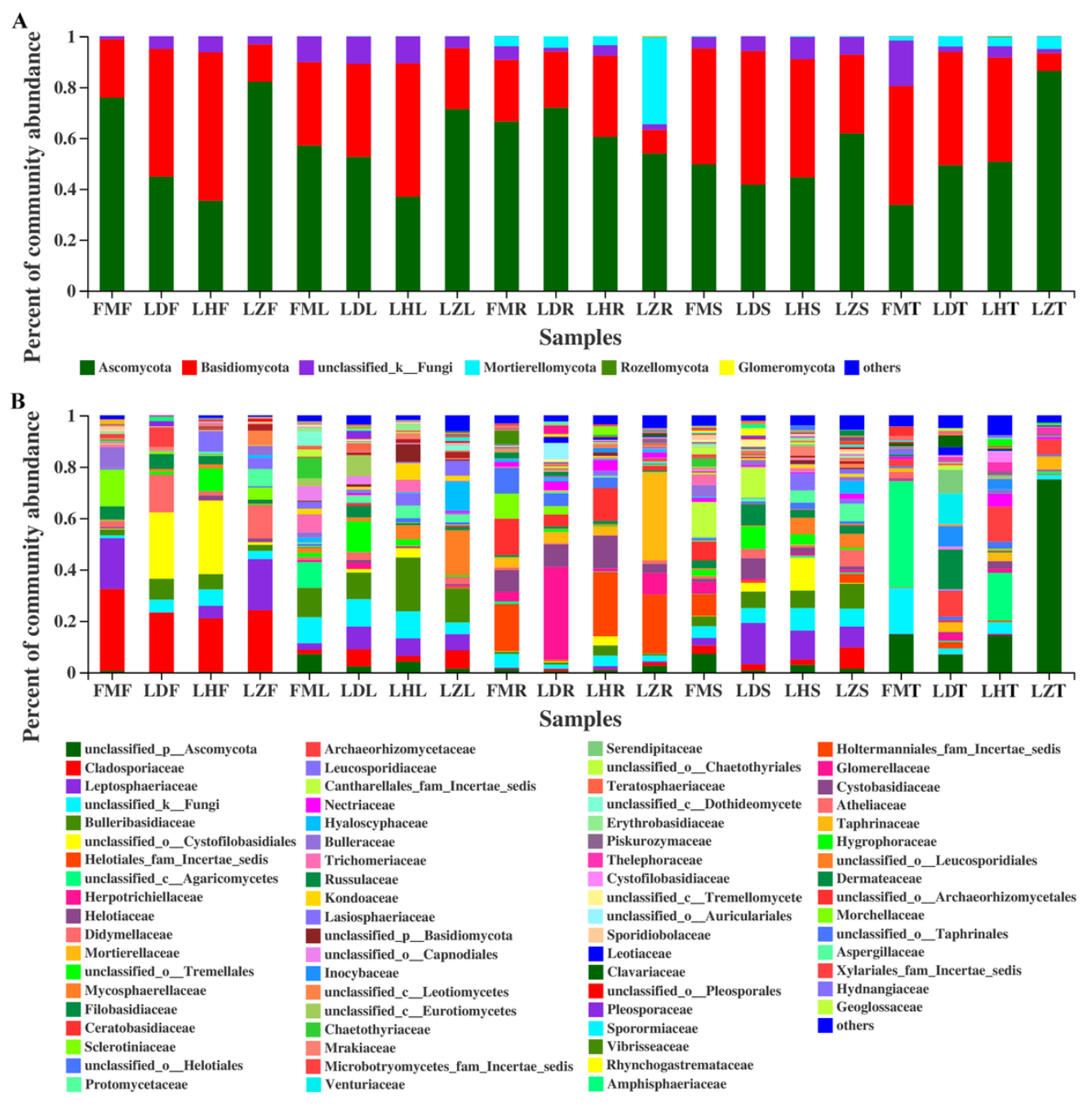

Figure 3

The abundance of fungal communities from different tissues and rhizosphere soils at the phylum (A) and family (B) levels. 


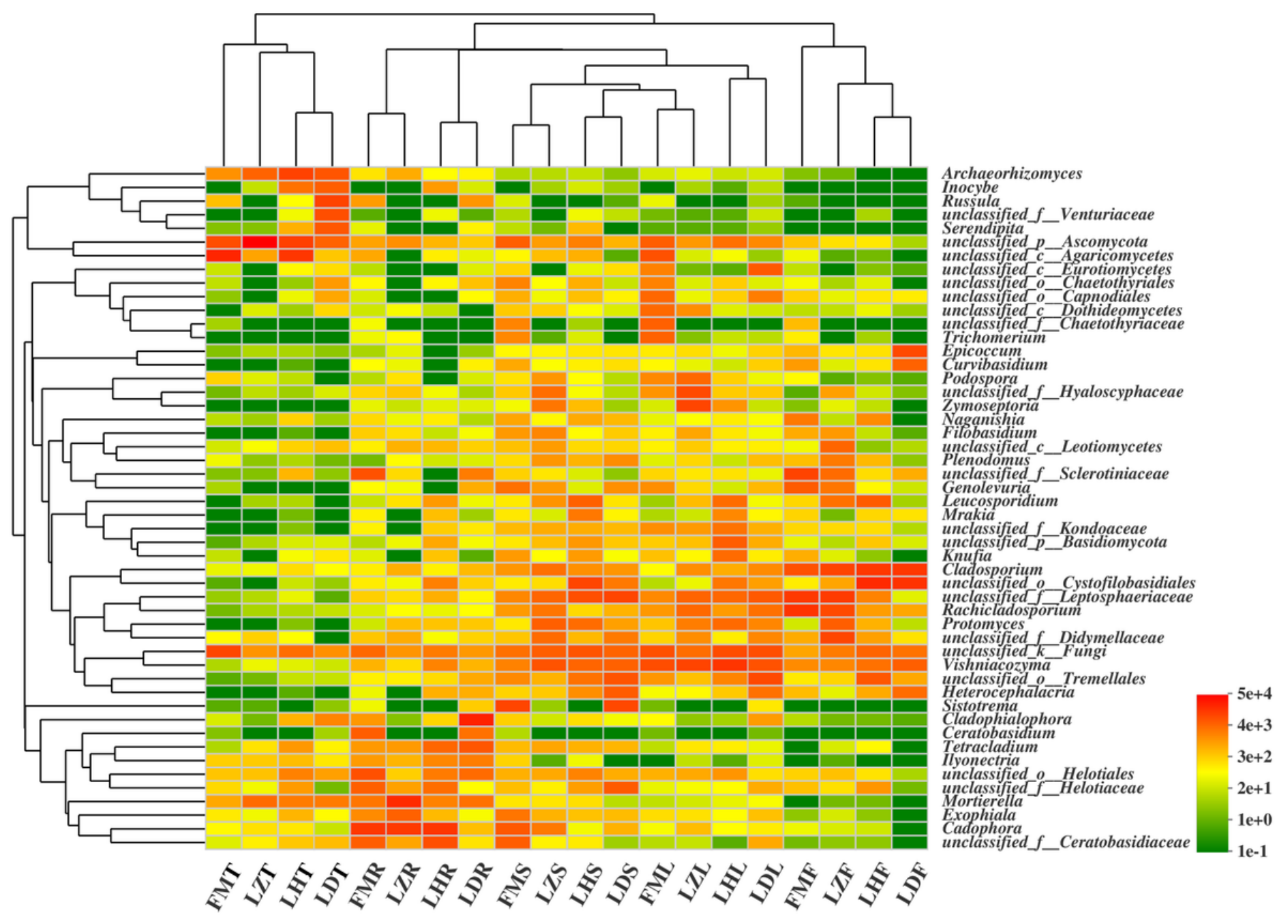

Figure 4

Heatmap of the fungal community (the top 50 most abundant genera) structure at the genus level. The color (from red to green) denotes the relative abundance (from high to low).
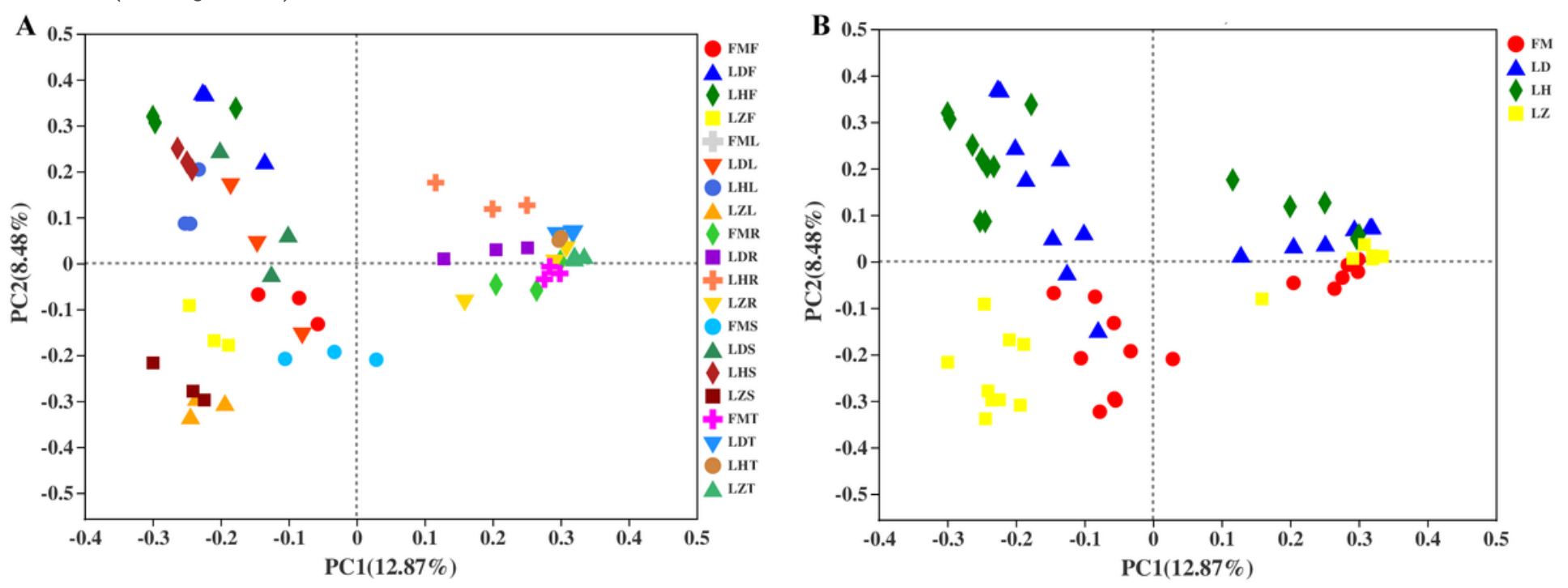

Figure 5

Principal coordinate analysis (PCOA) of the fungal community structure at the OTU level from all samples (A) and four sampling sites (B) with the intergroup differences tested by ANOSIM. The points of different colors and shapes represent the different samples. 

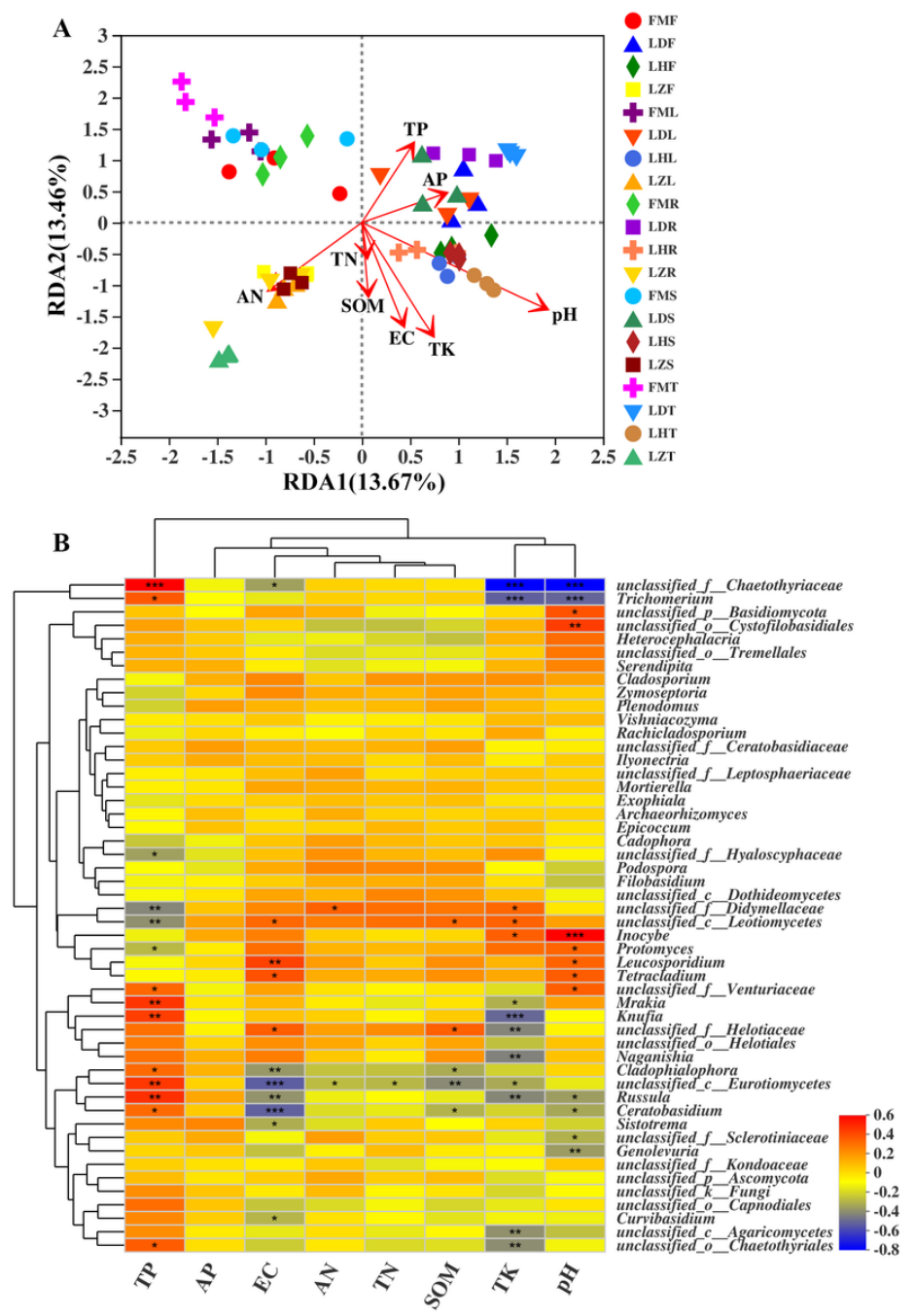

\section{Figure 6}

A. RDA of the relationship between fungal communities and the soil environment at four sites. The red vectors indicate the environmental factors affecting rhizosphere soils. B. Correlation heatmap of the microbial community (the top 50 most abundant genera) and the soil environment using the Spearman correlation coefficients. The $\mathrm{R}$ values are shown with different colors from red to blue representing the relative abundances from high to low. ${ }^{*}, *$, and $* \star *$ represent $\mathrm{p}$-value thresholds $(0.01<\mathrm{P} \leq 0.05,0.001<\mathrm{P} \leq 0.01$, and $\mathrm{P} \leq 0.001$, respectively).

\section{Supplementary Files}

This is a list of supplementary files associated with this preprint. Click to download.

- Tables1.xlsx 